Digital Badges in Afterschool Learning: Documenting the Perspectives and Experiences of Students and Educators

\author{
Katie Davis* \\ University of Washington \\ The Information School \\ Mary Gates Hall, Suite 370 \\ Box 352840 \\ Seattle, WA 98195 \\ USA \\ tel: (206) 221-7741 \\ fax: (206) 616-3152 \\ kdavis78@uw.edu \\ Simrat Singh \\ University of Washington \\ The Information School \\ * Corresponding Author
}




\title{
Digital Badges in Afterschool Learning: Documenting the Perspectives and Experiences of Students and Educators
}

\begin{abstract}
This paper explores the opportunities and challenges associated with implementing a digital badge system that awards high school credit for students' participation in after school programs serving non-dominant youth. Data include interviews and focus groups with 43 students, and interviews with 24 teachers and afterschool mentors and one college admissions director. Across all stakeholders, the most frequently cited opportunity related to the potential that badges hold for establishing learners' credibility outside the context in which their badges were earned by providing a trustworthy record of the skills and achievements that students gain through their participation in the afterschool programs. However, credibility also emerged as the dominant challenge associated with digital badges. Participants observed that in order for badges to succeed in proving one's credibility to external audiences, these audiences - such as college admissions officers and employers - must know about and recognize the validity of badges. Students, teachers, and program staff all expressed the belief that this essential criterion had not yet been achieved. We examine these findings in light of theory and research on the role of artifacts within and outside the communities of practice in which they were created and used. The findings hold implications for designers of openly networked learning environments that seek to span and connect diverse social settings.
\end{abstract}

Keywords: digital badges; gamification; human-computer interface; informal learning; secondary education 


\section{Introduction}

Out-of-school settings represent rich contexts for learning, providing youth with opportunities to take part in learning activities that are personally meaningful and engaging (Bell, Bricker, Reeve, Zimmerman, \& Tzou, 2013; Crowley, Barron, Knutson, \& Martin, in press). Unfortunately, for many youth, informal learning experiences go undocumented and unrecognized beyond the setting in which they occur. As a result, these young people miss opportunities to form connections between their informal and formal learning experiences, connections that would likely serve to deepen the learning that takes place in each setting (Ito et al., 2013). Also missed are opportunities to use the skills and achievements gained in informal contexts to unlock future educational and jobrelated experiences.

With the emergence of openly networked technologies, excitement has grown over the potential for such technologies to address these missed opportunities, particularly for youth from non-dominant backgrounds, who are defined as members of diverse cultural groups that have traditionally been excluded from institutionalized sources of privilege (Gutierrez \& Rogoff, 2003; Ito et al. 2013). Though the potential is there, affluent youth continue to enjoy the greatest opportunities to experience rich learning experiences with new media technologies (Hohlfeld, Ritzhaupt, Barron, \& Kemker, 2008; Ito et al., 2013; Neuman \& Celano, 2012; Zhong, 2011). Addressing this participation gap in technology use represents an ongoing challenge to leveraging openly networked technologies to promote social equity (Jenkins et al., 2009).

Digital badges represent a specific kind of networked technology that has the potential both to recognize and connect learning across contexts. As web-enabled digital icons containing metadata associated with specific learning goals, practices, and outcomes, digital badges are an alternative credentialing system aimed at recognizing and rewarding learning across a variety of domains, both inside and outside of formal educational contexts (Gibson et al., 2013; Grant, 2014). Though there is considerable enthusiasm and speculation around using digital badges to promote educational change, whether they succeed at empowering learners and connecting their learning across contexts remains largely untested (Riconscente, Kamarainen, \& Honey, 2013). Particularly lacking is knowledge of the value that key stakeholders-including youth themselves - ascribe to particular badges and badge systems. The current study addresses this gap in existing literature by documenting the badge-related experiences and perspectives of students, teachers, and staff affiliated with an afterschool program that serves youth from predominantly low-income, immigrant backgrounds. Through our analyses of interviews and focus groups, we identified the dominant opportunities and challenges that these stakeholders perceived with respect to using digital badges in their afterschool setting. The findings provide new insight into factors affecting the success or failure of implementing a digital badge system in informal learning contexts.

\subsection{Theoretical context}

The theoretical context for this study is grounded in situated theories of learning, which emphasize the social, contextualized nature of learning (Brown, Collins, \& Duguid, 1989; Lave, 1988). According to this perspective, learning is an inherently 
relational process that takes place as people negotiate meaning in specific social contexts (Lave \& Wenger, 1991). Evidence of one's learning is similarly negotiated among actors who are embedded in distinct social systems, each with its own set of norms, values, artifacts, and practices. As one type of learning evidence, digital badges must be considered within the social contexts in which they are used. As digital, easily transportable artifacts, they must also be considered in light of the meaning they are able to communicate across contexts. In what follows, we draw on relevant theory and research to explore how badges might operate within and across specific contexts.

It is now well understood that learning is supported when students are given the opportunity to take on meaningful roles within a community of practice (Lave \& Wenger, 1991; Wenger, 1998). For instance, in their study of high school students' participation on a basketball team and in a mathematics classroom, Nasir and Hand (2008) examined the mechanisms by which youth became engaged in and identified with each domain. They found that engagement and identification deepened as youth were given the chance to take on integral roles and when they were recognized as competent, valued contributors within the community of practice. They defined the term practice-linked identities to describe the sense of agency that learners feel when they experience a personal connection to a domain. In subsequent work, Nasir and Cooks (2009) found evidence of similar processes at work as high school students developed practice-linked identities in track and field.

This conception of a socially embedded identity developed through consequential participation in an activity aligns with Holland et al.'s (1998) agency-identity framework. According to this framework, identity is not a fixed essence that is formed and contained within an individual. Rather, it is an ever-evolving construct whose meaning is negotiated continuously through social interaction. As a result, one's sense of identity is integrally tied to the perceptions and reactions of others. The roles, discourses, and practices available to individuals shape how they negotiate their identities within a community of practice. Learning is embedded in these negotiations as individuals' positions and perspectives change with their changing identities (Lave \& Wenger, 1991). This practice theory of identity has been explored in subsequent studies investigating the intersection between socially constructed identities and learning (Barton \& Tan, 2010; Bell et al., 2012, 2013).

Artifacts play a central role in Holland et al.'s (1998) agency-identity framework. Artifacts represent mediating devices that communicate meaning within a social context - or figured world - and help to position people within that context. In this way, individuals use them as "tools of identity" to establish their roles and help shape how others see them (Holland et al., 1998, p.42). According to Holland et al., artifacts can be tangible objects, such as the poker chips awarded for sobriety in Alcoholics Anonymous, or they can be intangible symbols, such as the pronoun used to refer to a wife. A digital badge represents a type of artifact that communicates, through its visual icon and metadata, an individual's skills, achievements, or interests. When artifacts position a person as competent and skilled, they contribute to a sense of personal agency. Drawing on Vygotsky's (1978) concept of pivotal objects, Holland et al. argue that it is "...their capacity to shift the perceptual, cognitive, affective, and practical frame of activity - that makes cultural artifacts so significant in human life" (1998, p.63). In short, artifacts open 
up new possibilities for being and acting through their ability to communicate meaning among people.

Collectively, this body of work establishes the importance of providing learners with the opportunity to take on consequential roles and gain recognition from others for those roles. Such recognition shapes how learners see themselves and, consequently, how engaged they become in a particular learning activity or domain of inquiry. With their ability to communicate meaning between people, artifacts are central to this process. To that end, there is growing interest in the potential for digital badges - a specific type of artifact - to support learners' engagement in a domain by providing a way for them to gain recognition for their skills and achievements (Riconscente et al., 2013).

\subsection{Digital badges within and across learning settings}

Existing research on digital badges, though still emergent, provides some insight into the impact of badges on individuals' levels of engagement in certain activities. In one study, for instance, a badge-based achievement system was introduced into an online learning tool used by college students (Denny, 2013). A randomized controlled experiment involving over 1,000 students found evidence for the positive impact of badges on students' levels of participation. Specifically, badges increased the quantity of students' contributions and length of time they engaged without decreasing the quality of their contributions. In addition, students reported high levels of enjoyment and a preference for having badges incorporated into the online interface. In a separate experimental study investigating the effects of assigning editing awards or "barnstars" to Wikipedia contributors, Restivo and van de Rijt (2012) found that receiving barnstars increased the productivity of the experimental group by $60 \%$ compared to the control group. Other research has produced more mixed results, and suggests that the motivational effects of badges may vary according to interactions among the individual, activity, and type of badge awarded (Abramovich, Schunn, \& Higashi, 2013; Boticki, Baksa, Seow, \& Looi, forthcoming; Filsecker \& Hickey, 2014). Together, these studies do not appear to support the fears expressed by some that badges will decrease levels of intrinsic motivation by emphasizing extrinsic rewards (see Riconscente et al., 2013). Instead, they support a situative perspective on motivation, in which extrinsic and intrinsic motivation each play a role in supporting meaningful participation in a learning activity (Hickey \& McCaslin, 2001).

Beyond increasing levels of engagement in a discrete activity, badges may also promote longer-term engagement by supporting deepening levels of participation over time and across contexts. As learners gain skills and knowledge in a particular domain of inquiry, they transition from peripheral participation in a community of practice to a deeper, more integral form of participation (Lave \& Wenger, 1991). This progression can be characterized as a learning pathway, defined by Bell and colleagues as a series of linked actions that result in progressively deeper participation in a domain that is personally consequential (Bell et al., 2013). Unfortunately, learning pathways are often quite opaque to learners, resulting in a poor understanding of the steps needed to develop expertise in a domain. It can be particularly challenging to make visible the learning pathways available to youth outside of school, as informal learning experiences are typically not documented to the same degree as they are in formal educational settings 
(Bell et al., 2013). There is growing enthusiasm around using digital badges to increase the visibility of learning pathways in formal and informal contexts, thereby giving learners a sense of control and ownership over their learning experiences (Riconscente et al., 2013). As micro-credentials documenting specific skills and achievements, badges are well positioned to highlight the intermediate phases through which individuals pass as they deepen their expertise in a domain. By documenting where learners have been, badges can signal where they should go next.

Bell and colleagues point out that learning pathways can span multiple contexts (Bell et al. 2013). However, it can be difficult to form connections across settings that have their own sets of norms, values, and practices. As mediating devices, artifacts can facilitate these cross-context connections. When artifacts are used to communicate meaning across contexts, they serve as boundary objects that make it possible to translate the values and practices in one setting to the values and practices in another setting (Bowker \& Star, 1999; Star \& Greisemer, 1989).

Credentials represent a specific type of boundary object that help individuals signal their skills and qualifications to external audiences, and, in turn, help gatekeepers such as employers make judgments based on the information signaled by individuals (Bills, 2003). For instance, college transcripts help communicate students' skills and accomplishments to audiences outside the institution in which they were acquired, such as parents and prospective employers.

Halavais (2012) observes that badges have the potential to act as ideal boundary objects. He points to initiatives such as Mozilla's open badges infrastructure (OBI), which provides a means to standardize badge metadata and enable interoperability across online platforms. Acknowledging the potential of Mozilla's OBI, Rughinis (2013) notes that considerable interpretive work is still required to make sense of badge collections, raising challenges with respect to validating the credibility of badges earned in diverse contexts. Indeed, key stakeholders associated with digital badges in education — such as educators, students, badge system designers, and prospective employers - have expressed concern about knowing how to judge the value of a particular badge as it moves across contexts (Davis \& Klein, 2015; Fullerton et al., 2014). As well, in a recent investigation of digital badges, high school students expressed resistance to the idea of sharing education-related badges on social media platforms that they experience as primarily friendship-driven spaces (Davis \& Fullerton, forthcoming; Davis \& Klein, 2015). If badges are to become widely recognized and valid forms of credentials, we need a better understanding of the value that such stakeholders perceive in badges, including how they interpret their meaning, and the opportunities and challenges they perceive in using badges to recognize learners' skills and achievements.

\subsection{The current study}

The current study explores the opportunities and challenges associated with implementing a digital badge system that awards high school credit for students' participation in a network of afterschool programs serving youth from low income, immigrant backgrounds. Through interviews and focus groups with 43 students, as well as interviews with 24 teachers and afterschool mentors and one college admissions director, we explored the following research questions: 
Research Question 1: How do students and teachers engage with and experience badges in the Afterschool Network's Expanded Learning Experiences (ELEs) ${ }^{1}$ ? Research Question 2: What opportunities and challenges do stakeholders perceive in the use of digital badges to recognize afterschool learning?

\section{Method}

\subsection{Research site}

The research site comprises a network of afterschool programs, the Afterschool Network (AN), which serves high school students attending public school in an urban city in the Northeast United States. In 2008, the AN launched a new high school initiative to build on the organization's long-standing and well-respected middle school programs. In 2012, students in one high school began receiving elective credit for participating in these afterschool programs, which the AN calls Expanded Learning Experiences (ELEs). During the same year, the AN began awarding digital badges to students for their successful completion of ELEs. These digital badges are displayed on students' profiles on the website associated with the ELE program, called CentralSite. Because the ELE program was still relatively small (approximately 35 students) and located in just one school, the AN was able to host a badge award ceremony at the end of the term for all students. In this ceremony, the staff explained to students what badges were and showed them how to claim and display them online.

This badge implementation approach was not sustainable as the ELE program expanded to a second high school in fall 2013 and a third school in spring 2014. As a result, students participating in ELEs for the first time in 2013 and later received no formal training or education around the badge system. Community partners and teachers of record were somewhat more familiar with badges because the AN staff continued to discuss badges in the teacher trainings at the start of each year. However, these discussions did not involve showing community partners and teachers of record actual badges displayed on the CentralSite website.

\subsection{Sample}

Data include interviews and focus groups with 43 students, and interviews with 24 teachers and afterschool mentors and one college admissions director. Researchers asked questions about participants' knowledge of and experiences with digital badges in the context of the ELE program; how they saw badges fitting in with the goals and activities associated with the ELE program; and their perceptions of the opportunities and challenges associated with digital badges.

\subsection{Data collection}

Adult sample. Eight of the 25 adult participants were service providers working directly with high school students at various after school programs, some of which take place at the students' schools and some at other locations around the city. Six of the

${ }^{1}$ All names provided are pseudonyms to protect the privacy of study participants. 
participants were teachers of record for ELE programs. As high school teachers employed by the school district, teachers of record are responsible for assigning students' grades and deciding whether students receive high school elective credits for their participation. Teachers of record observe ELE sessions during the semester; read and respond to students' blogs; and take part in the judging at the Exhibition Event at the end of the semester. Ten interviewees were current or former AN staff involved with the planning, implementation, and/or evaluation of ELEs and the badge system. The final interviewee was a college admissions director whose college had received student applications that included digital badges from the ELE program.

Student sample. We also conducted eight in-person focus group interview sessions or student pair interviews with a total of 43 students between October and April 2014. The students who participated in these sessions reflect the demographic characteristics of the broader student population in the public school district. Of the 6,516 high school students enrolled in the school district in 2013-2014, 72\% qualified for free or reduced lunch; 63\% identified as Hispanic; $19 \%$ were Black; $10 \%$ were White; and the remaining $8 \%$ identified as either Native American, Asian Pacific, or Multi-Race. ${ }^{2}$

\subsection{Data analysis}

The interviews and focus groups were audio-recorded and transcribed verbatim. Using thematic analysis (Boyatzis, 1998), codes were developed etically - by drawing on the research questions and relevant literature - and emically - by identifying themes that emerged inductively from the perspectives of participants (Maxwell, 2005). Researchers identified an initial "start list" of opportunity and challenge codes (Miles \& Huberman, 1994) by referring to related work exploring stakeholders' perceptions of digital badges in education (Davis \& Klein, 2015; Fullerton et al., 2014). For example, we drew on Hickey's Design Principles Documentation Project to identify codes related to recognizing, motivating, and assessing learning (Itow \& Hickey, 2013; Rehak \& Hickey, 2013; Schenke, Tran \& Hickey, 2013). To the extent possible, for every opportunity code we identified a parallel challenge code. For instance, one of the opportunity codes is "use badges to establish credibility, reputation, skills." We created a parallel challenge code described as "challenge of establishing credibility, getting stakeholders to value badges."

Two researchers then read through the entire set of transcripts to ensure the codes were appropriate and specific to the current dataset. Codes were refined through ongoing discussions during this process. These initial readings and discussions also led to the identification of additional emic codes that emerged directly from the data. Due to the nature of these emic codes, not all opportunity codes have a corresponding challenge code. The full set of codes is listed in Appendix A.

To ensure the codes were applied consistently and accurately to the entire dataset, we employed a joint, iterative process of collaborative discussion and independent corroboration (Smagorinsky, 2008). In the first stage of analysis, two researchers independently applied the top-level codes (awareness of badges, opportunities, challenges) to a transcript selected at random. We calculated kappa statistics for each

${ }^{2}$ Citation withheld to protect the privacy of study participants. Data were obtained from the state department of education. 
code, documented areas of agreement and disagreement, and then clarified through discussion the definition and appropriate application of each code. Following guidelines suggested by Landis and Koch (1977), we repeated this process a second time, until acceptable levels of Kappa (above 0.60) were obtained. The final kappa statistics associated with awareness of badges, opportunities, and challenges were 0.76, 0.95, and 1.00 , respectively.

In the second stage of analysis, one researcher took the role of primary coder and applied the opportunities and challenges sub-codes to a transcript selected at random. A second researcher served as the "shadow" coder and checked the codes applied by the primary coder to this transcript. The two researchers met to discuss areas of agreement and disagreement. After arriving at consensus on the application of sub-codes, the primary coder independently coded two additional transcripts selected at random, with the shadow coder checking the codes directly afterward. The two coders met a second time to discuss areas of agreement and disagreement and come to consensus on the final codes. This process was repeated nine times until all transcripts were coded and full consensus achieved.

During the coding process, both the primary and shadow coders identified numerous connections among individual codes. For instance, statements relating to credibility were often coded next to statements relating to actionability and recognition. By examining the connections among codes, we identified four dominant themes relating to the opportunities and challenges associated with digital badges: (1) Establishing credibility: A chicken or egg problem; (2) Motivating learners; (3) Empowering students through learning pathways; and (4) Integrating badges into existing practices: Logistical and institutional challenges. We have organized the findings relating to opportunities and challenges around these four themes.

\section{Findings}

\subsection{Participants' awareness of and experiences with badges}

As noted above, digital badges are awarded to students for their successful completion of ELEs and displayed on their individual profile pages on the CentralSite website. When the first batch of badges was awarded in spring 2012, the ELE program was operating in one high school only. Students were invited to a badge awarding event at their high school, where the AN staff explained to students how to access their badges online and where they were displayed on their CentralSite profile pages. As the ELE program grew in size-both the number of students and schools participating and the number of programs offered - the badge awarding event was discontinued due to the logistical challenges associated with an expanding program.

During the 2013-2014 academic year when this study was conducted, students were largely unaware of the badges, indicating that they had never heard of digital badges before our interviews. For instance, when we asked students in one focus group if they knew anything about digital badges, the answers we received included: "What is that?" "What do you mean?" "Nobody knows about that." Even for those students who said they had some knowledge of badges, many were not aware of how to earn them or where 
their earned badges were displayed. ${ }^{3}$ One student said: "I don't know how to get them." When asked if they had seen badges on their CentralSite profile, one student answered: "I've got to check that out." Another student stated: "I think I've seen one, but I don't know what it is." This lack of awareness existed despite the fact that all students had visited the CentralSite website to view their profiles and use the blog features there. By contrast, all students were aware that they would receive high school credit for their successful participation in the afterschool program. Indeed, students identified the prospect of earning course credit as the primary motivation for taking part in afterschool activities. They did not see any connection between digital badges and course credit. Commented one student: "What's the point of the badge if you just get a grade?"

The teachers and community partners expressed a similar lack of awareness of badges. One community partner stated: "I wasn't aware of them last session. Were there any last session or is it all new?" Even for those educators who knew something about badges, much of their knowledge came indirectly through hearing the AN staff talk about them during program trainings. One community partner told us: "I heard about them through the AN's training courses, I guess, when we went in, and they told us about what they were working on." This awareness did not always translate into an understanding of how badges were used in the ELE program. One teacher we interviewed explained:

I'm a little confused about the badges because I never saw a student with

a badge. I heard that the kids were going to get badges and they were going to get awards on it and they could put digital information on it but I never saw one kid with a digital badge. So I'm not really sure. I would hear the phrase a lot but I would never see the product.

This teacher's comment is reflective of those educators who had some secondhand knowledge of badges but were unsure of how they were awarded, where they were displayed, or how they fit into the rest of the ELE program.

\subsection{Potential opportunities, current challenges}

The responses given by students, community partners, and teachers in the preceding section indicate that badges had not yet been integrated fully into the ELE program at the time of the current study. Nevertheless, participants had much to say about both the potential opportunities and current challenges associated with using digital badges in afterschool settings. Tables 1 and 2 summarize the most frequently cited opportunities and challenges, separated out by stakeholder. Because our analysis uncovered connections across individual codes, the dominant opportunities and challenges are grouped and discussed thematically in the following sections.

[Tables 1 and 2 about here]

\subsubsection{Establishing credibility: A chicken or egg problem}

\footnotetext{
${ }^{3}$ Because most students were interviewed in focus groups, we are unable to report the exact number of students who endorsed a particular viewpoint.
} 
Across all stakeholders, the most frequently cited opportunity related to the potential that badges hold for establishing learners' credibility outside the context in which their badges were earned (Table 1). Overall, 29\% of the opportunity statements (125/425) related to credibility. Students, teachers, and AN staff were enthusiastic about the prospect of using badges to provide a trustworthy record of the skills and achievements that students gain through their participation in the ELE programs. One student stated: "With the [CentralSite] website you can see the digital badge. If you put that on your college resume, they [college admissions officers] can actually look at it and see how much work you've done." Similarly, another student explained: "It's supposed to show up in your transcripts...And so when you're applying to colleges, colleges see like, you know like it wasn't just like an extracurricular, it was like actual work. Which I think gives it a lot more credibility." One of the teachers explained the potential of badges in this way:

I think that colleges - the fact that a college admissions officer can see that a student did something above and beyond school that they did not have to do - it was not required; it was out of school time, and it was learning, and they earned a credit for it, but it was a dedication and a commitment to learning something on their own - says a lot about that student. With the digital badging now, as people become more aware of what digital badging means, it'll tell anybody who's looking at a student's transcript. If there's a digital badge associated with it, they'll know, 'Well, that digital badge means that that student met X, Y, and Z criteria.' These kids will be able to have transcripts that show learning that they could not accomplish in a traditional school day.

Statements such as these suggest that a core benefit that participants perceive in digital badges relates to their ability to document and verify to external audiences learning that takes place outside of school and that has typically gone undocumented and unverified.

At the same time, credibility also emerged as the most frequently cited challenge associated with digital badges, with $31 \%$ of the total challenge statements (110/352) relating to credibility (Table 2). Participants observed that in order for badges to succeed at establishing one's credibility to external audiences, these audiences - such as college admissions officers and employers - must know about and recognize the validity of AN badges. Students, teachers, and AN staff all expressed the belief that this essential criterion had not yet been achieved. One community partner stated: "I guess my concern about it is the credibility of the digital badges... at this point [they're] not recognizable... but I also understand that it takes time to get certain things kind of rolling." Similarly, one student explained:

I think if they were advertised a bit more, more of a structured thing, where like a job would know you have certain skills because this badge is present, but I don't know how that would be on a résumé or something. Then yeah, like there would be benefits to doing it for the badge. But right now, it just seems like the badge is just something more symbolic, for your own.

Some participants referred to this challenge as a "chicken or egg" situation: Should badges be created and awarded first and then buy-in sought from key stakeholders like college admissions officers and employers? Or, should buy-in be sought first? The AN 
has followed the first route, with the result being that students said they do not value badges because they do not believe anyone outside the AN values them.

The second and third most commonly cited opportunities - actionability and recognition - are directly related to the ability to establish one's credibility to external audiences. Students and community partners were the most likely to comment on the opportunity to display badges publicly online and thereby gain widespread recognition for one's achievements (Table 1). One community partner said: "I like the idea of the students collecting badges, kind of like Boy Scouts, to show off their achievements." Similarly, a student commented: "If you get a digital badge and it's on your profile, it shows people what you've accomplished." Yet, as noted above, the current low degree of badge awareness among stakeholders poses challenges to using them for the purpose of gaining recognition from external audiences. Indeed, this challenge of visibility was the third most frequently cited challenge, representing $11 \%(38 / 352)$ of all challenge statements.

With respect to actionability, participants, particularly AN staff, recognized the opportunity to use the public and trustworthy record of one's skills to unlock future education and career opportunities. One AN staff member remarked:

I think adults coming together to validate student learning outside of classes that are not serving them well and helping them to leverage those towards new experiences and opportunities, that feels like a really nice narrative that I can understand why that all would exist.

However, reflecting the widespread recognition among participants that the badge system in its current form is not yet unlocking such opportunities for students, the same participant went on to say: "Do I think our badges are currently doing that? No. Do I think they could? Maybe." According to this and other participants, the primary impediment to unlocking future opportunities relates to the chicken or egg problem discussed above. Badges will not unlock tangible opportunities for students until they hold value for key stakeholders such as college admissions officials and prospective employers. However, in order for these stakeholders to buy into badges they must be convinced of their worth.

An additional challenge associated with establishing the value and credibility of badges pertains to issues of quality control. One AN staff member observed: "An arts program can create a badge... But if it's too shallow and it's all over the place, it's going to be hard for people to sort you know, crap from good stuff." Another AN staff member expressed concern about awarding badges based solely on participation: "We first of all need to get beyond digital badges for participation. Like it should not be just because I participate, therefore I get a badge. It waters it down, it means nothing doing this." This participant saw awarding such participation-based badges as a key impediment to gaining broad stakeholder buy-in for badges. A student expressed a similar sentiment when he said: "I just feel like what's the point of a digital badge if...everyone basically got it."

\subsubsection{Motivating learners}

Participants recognized both potentials and challenges associated with using badges to motivate learners (Tables 1 and 2). Indeed, motivation constituted the second most frequently cited opportunity by teachers. Comments associated with the positive 
motivating role of badges tended to mention the promise of gaining reward or recognition. With respect to reward, one teacher reflected: "Anytime a student receives merit or credit they seem like they want to do more and they get more involved. I mean [that's the case] with any type of incentive." With respect to recognition, one student commented on the motivating role that seeing others' badges publicly displayed might play in students' desire to earn their own badges: "It inspires people... in a way that if their friends are earning, maybe they'd think about it. They might say oh, they're earning, like why shouldn't I?"

Both students and adults tied the motivational aspect of badges to their potential to unlock real opportunities for students. One student stipulated that she would be motivated to earn badges provided they helped her get into college: "I would show them [publicly online] and I will do everything to earn it." Similarly, a community partner expressed the belief that badges will only be motivating to students if they are valued by external audiences and able to unlock concrete opportunities: "If there was buy-in from the people for whom it should matter [like colleges], then I think it could motivate students. But if there isn't that buy in, I don't know how it would motivate them."

Reflecting the current lack of stakeholder buy-in, several students declared they were not currently motivated by the prospect of earning badges. One student declared: "Badges don't motivate me. I'm doing it because of my own personal interest." This student's statement also surfaces a concern expressed by eight of the 25 (32\%) adults interviewed that digital badges, operating as an extrinsic motivator, could prove detrimental to students' intrinsic motivation to learn. One community partner stated: "I think centering the pursuit of digital badges as the ultimate opportunity of engaging in an ELE, I think that's something that everyone needs to be cautious about." Similarly, one AN staff member commented: "I would be hoping that we would be emphasizing building an intrinsic, personal motivation to learn over you learn because you get something." In contrast, another AN staff member explained why she was not concerned about a trade-off between intrinsic and extrinsic motivation: "I don't think a single badge is going to give anybody motivation to do something they don't already want to do. I think it just is a little bit of a nudge."

\subsubsection{Empowering students through learning pathways}

Both adults and students expressed optimism about the potential for badges to empower students by placing them in control of documenting and displaying their learning. As several AN staff explained, the metadata associated with badges provide rich, visible documentation of learning so that students know exactly what they need to do in order to earn a particular badge. Moreover, the digital form and interoperability of badges are intended to allow students to display their learning to specific audiences and on platforms of their choosing. As a result of these properties, badges have the potential to increase the visibility and transparency of learning trajectories, making it possible for students to choose where to go next in their learning. One AN staff member described the relationship between badges, learning pathways, and empowerment in the following way: "[With badges], individuals of any age can put together, curate, and then follow their own highly individualized learning pathways with their own goals and outcomes in mind."

Key to this statement is the idea of placing students in control of their learning. 
While students did not talk explicitly about learning pathways, they did express optimism about the potential for badges to play a positive, empowering role in their learning. In one focus group, students pointed out that, unlike grades, badges are awarded for positive achievements. One of the student participants reflected: "[Instead of] showing the negative side, [badges] show much more of the good side of what you've done." By contrast, she explained, grades show both failure and success. Another student explained why she thought that badges were a fairer way to assess students than grades:

My friend from [neighborhood school] last year did an ELE, the debate ELE, but she wasn't a native speaker. And so I'm saying if you create a rubric for these ELEs where you either get a $100 \%$ or what they talk about, this is a hundred, this is a ninety, this is an eighty and so on and so on. I think you create a structure that people don't want to be in because you'll feel, like I think, it's really unfair for some people. Especially because ELEs are I think meant to be inclusive and very supportive.

This student is pointing out the value in breaking out of the traditional system of assessment, which is experienced as unfairly biased against them by many underrepresented students, such as non-native English speakers. Collectively, these youth statements indicate that students recognize in badges a mechanism to create a fairer means of assessment, one that emphasizes their successes rather than failures.

Several adult participants linked having control over one's learning trajectory to issues of equity in education, observing that the students served by the AN typically do not receive as much support as students in more affluent school districts in packaging their skills and accomplishments for external audiences such as college admissions officers and prospective employers. One AN staff member explained:

[Badges have] value for our students... when they are competing against students from suburban schools that have access to like really bad [sic] astrobotics clubs and things like that...I mean this is a very unique opportunity for [our students] to stand out against other [more affluent] students in college...If my kid can HTML code and he's competing against a bunch of kids that have more opportunities, more affluent backgrounds, like that's sort of where we're positioned to make a difference [with badges].

This participant observed that badges have the potential to help narrow the disparity between more and less affluent students by providing the means for less affluent students to document and display their learning in a way that they typically receive little support in doing but which is common practice among affluent students. In a similar manner, another AN staff member observed:

A badge might be an easy translation so that kids who aren't really trained to talk about their learning experiences and talk about what they've done - and no senior in high school gets - or at least not in [this school district] - really gets a good education in how to...sell your experiences or how to talk about things you've done besides the grades you've gotten and things like that. So if a badge does that, that's where I think the potential is. 
Related to these comments about personal packaging, one community partner reflected specifically on the opportunity for students to craft a positive online presence:

I also think it is a good opportunity to change people's online presence for the good you know, to give them something [positive to show] when they go to a job [interview] someday... Right now if you can Google their name, you get their Facebook. You know, it's having an alternative to Facebook chat showing up [in a] Google [search].

Like the two AN staff members quoted above, this participant also commented on the disparity between more and less affluent youth with respect to the level of support they receive from adults and peer mentors concerning their strategies for curating a positive online presence and digital footprint.

While learner control and empowerment represents a central goal of digital badges, several participants noted that the current ELE badge system was implemented and is now administered in a decidedly top-down manner. One AN staff member stated: "Quite frankly, I think for many students right now, they (A) don't know what a badge is, and (B) don't give a crap about a badge. I think it's an adult construct, by and large." When asked what he thought of badges, one student responded flatly: "Horrible." Asked why he felt that way about badges, he explained: "Because I didn't make it my own. I wanted to make it look like the way I wanted to make it look."

Students also expressed the desire to maintain control over where and to whom they display their badges. Proponents of digital badges celebrate their ability to facilitate connections across contexts so that skills and achievements gained in one setting can be recognized and used to unlock future opportunities in another setting (Ito et al., 2013: Riconscente et al. 2013). However, the students in the current sample were not enthusiastic about the idea of sharing badges across certain online platforms. In fact, privacy concerns represented the third most frequently cited challenge among youth participants. When asked if he would want to display his badges on social network platforms like Twitter, Instagram, and Facebook, one student shook his head and said: "I don't want anybody to know, because like I want to keep that separate like one thing from the other." He went on to explain the different purposes of Twitter and the CentralSite website: "[Twitter is] to put your feelings, what are you doing...With the [CentralSite] website, you post like about the debate, what you're learning." Embedded in this quote and expressed explicitly by other students is an awareness of the different audiences on different online platforms. While students said they would like to show their badges to college admissions officers and prospective employers, they would not want to show badges to friends, preferring to maintain a separation between their academic and social worlds.

\subsubsection{Integrating badges into existing practices: Logistical and institutional challenges}

As the ones responsible for implementing the badge system, AN staff members were most vocal about the challenges associated with administering a badge system. In fact, the most commonly cited challenge identified by AN staff was the effort and work required to implement and scale the current badge system. This challenge accounted for $27 \%$ of all challenge statements (44/164) made by AN staff. Within the entire sample of participants, the effort and work associated with implementing a badge system emerged as the second most frequently cited challenge, behind the challenge of using badges to 
establish one's credibility. These statements addressed the work required to gain buy-in from key stakeholders such as students, teachers, college admissions officers, and potential employers. Specifically, AN staff pointed to the work involved in educating these stakeholders about what badges are, how to interpret them, and how to incorporate them into their existing practices. One AN participant reflected on the effort required to educate students in particular:

If you want to have large-scale impact with the digital badges, we do have to invest time in making sure that, again, the students have even a remote idea as to what it is, and then knowing the level, the range of sort of tech literacy [among students], what they have on their plate, just the struggle to get that college application in, period.

Implied in this statement is the recognition that in order for badges to play a positive role in promoting social equity (discussed in the previous section), students must be supported in developing the necessary digital literacy skills to use badges strategically to unlock future education and career opportunities. It is not enough simply to introduce badges and leave it up to students and other stakeholders to figure out how to use and make sense of them.

AN staff participants also had much to say about the technical challenges they face with respect to implementing a badge system in an under-resourced community. One AN participant commented on students' lack of access to computers: "These students don't all have computers at home. And sometimes, they aren't able to access computers at school." Even when students can get on a computer at school, one AN participant remarked: "[The] internet firewalls in our public schools most closely resemble China's firewalls." Indeed, the first badge awarding ceremony was complicated by the fact that the school at which it took place blocked access to the CentralSite website. A savvy student used a workaround to circumvent the school's firewall so that students could get on the site and claim their badges. Another AN participant tied these types of technical challenges to the goal of using badges to promote social equity in education: "I think badges can level the playing field, but the infrastructure and the supports need to be there for urban districts to actually allow them to catch up, because technically, they're 20 or 30 years behind."

\section{Discussion}

This study explored how digital badges were perceived and experienced by the students, teachers, and staff associated with an afterschool program that awards high school credit for students' successful participation in its programming. The findings provide new insight into the opportunities and challenges that key stakeholders associate with digital badges. The most frequently cited opportunity - credibility - was also identified as the biggest challenge to badge adoption. While participants recognized the value in being able to document students' afterschool learning and share it with a wide audience, they noted the difficulty of having this new form of credential recognized widely as legitimate, trustworthy evidence of students' skills and achievements. In this discussion, we consider this and other key findings in light of existing theory and research related to badges and their function as mediating devices and boundary objects. 
Our investigation of Research Question 1 revealed that badges operated on the periphery of the afterschool program during the period in which the study took place. Both students and teachers were largely unaware of badges. For those participants who had heard about them, badges were not playing a measurable role in their day-to-day experiences or motivation for taking part in the program. In contrast, all participants knew that successful participation in the afterschool program would result in earning high school elective credit. Course credit was something that students recognized and valued because it was directly tied to and affected their school experience. Badges, on the other hand, offered no such obvious benefit to students. Due to the lack of visibility and awareness of badges, participants' comments about the opportunities associated with badges were largely oriented to what they could potentially do, not what they currently did. The challenges focused more on the immediate, concrete obstacles to successful adoption of badges in the afterschool program.

As noted above, credibility emerged as the dominant opportunity and challenge associated with badge adoption (Research Question 2). Participants in the current study recognized the potential for badges to communicate trustworthy information about students' afterschool experiences by providing a visible, enduring record of achievement. This record includes credibility-signaling information such as the criteria for earning a badge, the specific evidence produced by the learner, and the identity of the badge issuer. Such documentation has typically been challenging to achieve in informal learning settings that operate outside the standards, assessments, and grades used to mark progress in formal educational settings (Bell et al., 2013). The potential to document and communicate credible information within and across contexts was associated with the second and third most popular opportunities cited by study participants: recognition and actionability. The visual icon and metadata associated with a badge provide visible documentation of a learner's accomplishments. Because they are digital and displayed online, badges have the ability to communicate information about learners to diverse audiences, including those that are internal and those that are external to the setting in which the badge was earned (Riconscente et al., 2013). Student participants expressed enthusiasm about the prospect of gaining recognition for their afterschool accomplishments from audiences they valued, particularly college admissions officers and prospective employers. Along with the adult participants, students appreciated the value in using this recognition to unlock future educational and employment opportunities. Taken together, these top three opportunities of credibility, recognition, and actionability tie into previous work underscoring the socially embedded nature of learning and the importance of being recognized for the roles one assumes within a community of practice (Holland et al., 1998; Nasir \& Hand, 2008). As mediating devices, badges have the potential to serve as "tools of identity" that help students establish their roles and shape how others see them (Holland et al., 1998, p.42).

In order for badges to serve as effective mediating devices, however, they must be recognized as holding real value by all relevant stakeholders, from students and teachers to admissions officers and prospective employers. The fact that credibility emerged as the most frequently cited challenge to badge adoption reflects the recognition among participants that the potential they saw in badges had not yet been realized. Their comments mostly centered on the stated belief that few people know what badges are or how to interpret the information they contain. AN staff participants discussed the 
"chicken or egg" conundrum of not knowing whether badges should be created first and buy-in from stakeholders sought later, or whether stakeholder buy-in should be secured before implementing a badge system. These reflections about the challenges of establishing credibility are consistent with Rughinis' (2013) observation that digital badges entail considerable interpretive work in order to function as successful boundary objects that negotiate meaning across contexts. He notes that the metadata associated with badges provide more nuanced information than traditional credentials. At the same time, this nuance requires more effort on the part of external audiences, who must evaluate and weigh badge metadata to make judgments about the nature of learning taking place across heterogeneous environments. The findings from the current study suggest that key stakeholders are not yet equipped to engage in this interpretive work, underscoring the challenge associated with introducing a new boundary object and establishing its meaning for all concerned parties.

Motivation emerged as a second overarching theme relating to the opportunities and challenges associated with digital badges. Earlier research exploring the motivational aspects of badges has produced evidence that badges have a positive influence on participants' levels of engagement in particular activities (e.g. Abramovich et al., 2013; Denny, 2013; Restivo \& van de Rijt, 2012). The findings from the current study add depth to this existing evidence by identifying reasons why participants do or do not find badges motivating. Both adults and students recognized the potential —as yet unrealized - for badges to motivate students' participation. However, several adult participants expressed concern that badges represented an extrinsic form of motivation and would therefore decrease students' intrinsic desire to participate in the afterschool programming. Our analysis suggests that a key motivating aspect of badges for students relates to their potential to unlock real opportunities outside the afterschool context. In other words, it is not the badge itself that motivates students but what it represents and the opportunities that it can introduce. While there is an element of extrinsic motivation in this view, it is nevertheless compatible with an intrinsic desire to participate in an activity. In this way, the students' views of motivation are well aligned with a situative perspective on motivation, which rejects a simplistic binary distinction between extrinsic and intrinsic motivation and focuses instead on the meaningfulness of students' situated participation in learning experiences (Hickey \& McCaslin, 2001). This perspective also explains why the motivating potential of badges has not yet been realized in practice. Students will not find badges motivating until they are recognized by and hold value to consequential audiences such as college admissions officers and prospective employers.

A third dominant theme from our analysis concerned the potential for badges to play an empowering role in students' lives by placing them in control of documenting and displaying their learning. AN staff in particular spoke about the ability for badges to increase the visibility and transparency of learning pathways by showing students their progress towards specific learning goals and the steps they must take to achieve their goals. This view is consistent with published work describing the potential for badges to support students' movement along learning pathways (Riconscente et al., 2013). As they progress along learning pathways, students deepen their participation in a domain (Bell et al., 2013). Though participants recognized this potential, they noted that the badge system in its present form neither placed students in control of their learning nor increased the visibility of their learning pathways. Participants attributed this disjunction between the 
potential and the reality of badges to the fact that the badge system had been created and introduced in a top-down manner by select AN staff. As a result, the system was seen by participants as an add-on that was not meaningfully integrated into their daily experiences in the afterschool program. Moreover, several students expressed a desire for greater control over where and to whom they display their badges. Consistent with previous research (Davis \& Klein, 2015), these students wanted to maintain clear boundaries between their peer contexts and school contexts, and were therefore resistant to the prospect of sharing their badges on sites like Twitter, Instagram, and Facebook.

The theme of student empowerment included discussions of social equity. Adult participants saw the potential for badges to give non-dominant youth a means to package their skills and accomplishments for audiences of import like college admissions officers and prospective employers. This view is consistent with Ito et al.'s (2013) connected learning framework, which highlights the potential for openly networked technologies to level the playing field between dominant and non-dominant youth. For their part, students also recognized an equity opportunity in badges by offering an alternative to traditional systems of assessment like grades, which they viewed as unfairly biased against them. At the same time, some adult participants expressed concern that badges could potentially widen inequity if affluent students are given more support in earning, curating, and sharing their badges.

Finally, as one of the first qualitative investigations of the implementation of a digital badge system, the current study provides new insight into the logistical and institutional challenges that accompany badge adoption in educational settings, particularly those located in under-resourced communities. These challenges include the hard work associated with educating and gaining buy-in from stakeholders located both inside and outside the setting in which badges are awarded. AN staff noted that this work became measurably greater when the afterschool program expanded from serving one high school to three. They did not have the manpower necessary to educate the increased number of students and teachers about badges or to provide support around badge administration. Moreover, because all three high schools were located in under-resourced communities, participants faced a variety of technical challenges, including difficulty accessing working computers and the schools' restrictive internet firewalls. These challenges threaten to exacerbate the participation gap identified by Jenkins and colleagues (2009), in which youth from dominant and non-dominant backgrounds experience unequal access to opportunities for participating with new media technologies.

\subsection{Limitations and future directions}

The in-depth interviews with student and adult participants yielded rich insight into stakeholders' experiences with and perspectives on digital badges. This strength, however, also represents a limitation of the current study, since caution must be used when considering the implications of the findings beyond this particular afterschool setting. Even within this setting, study participants represented a convenience sample; therefore, their comments may not be representative of the full range of perspectives held by the students and adults affiliated with the Afterschool Network. Nevertheless, care was taken to recruit widely from the afterschool program, and we are confident that the 
findings accurately represent the dominant views of stakeholders. As future research is conducted on digital badges in education, the findings from this study can be compared to those addressing different educational settings and types of learners. Eventually, the accumulated knowledge will lead to a better understanding of the circumstances under which badges support learning in diverse contexts and for diverse students.

\section{Conclusion}

Badges represent an alternative method of credentialing that promise to make learning pathways visible and help learners gain recognition for their skills and achievements across contexts. In recent years, badge systems have been introduced into a variety of educational settings, but they have yet to become a widely recognized form of credential. By documenting the perspectives of adult and youth participants in an afterschool program, the current study provides insight into the obstacles that must be overcome in order for badges to be introduced successfully into educational settings, particularly those serving non-dominant youth. These obstacles include gaining buy-in from key stakeholders, discerning the validity of a particular badge, accessing the networked technologies needed to engage with badges, and ensuring that badges fit within the goals and values of badge earners. This insight is crucial for designers and implementers of badge systems to understand if they are to succeed in their efforts to turn badges into a widely accepted, valued documentation of learners' skills and achievements. 


\section{References}

Abramovich, S., Schunn, C., \& Higashi, R. M. (2013). Are badges useful in education? It depends upon the type of badge and expertise of learner. Educational Technology Research and Development, 61(2), 217-232.

Barton, A. C., \& Tan, E. (2010). We be burnin'! Agency, identity, and science learning. Journal of the Learning Sciences, 19(2), 187-229.

Bell, P., Tzou, C., Bricker, L., \& Baines, A.D. (2012). Learning in diversities of structures of social practice: Accounting for how, why, and where people learn science. Human Development, 55, 269-284.

Bell, P., Bricker, L., Reeve, S., Zimmerman, H.T., \& Tzou, C. (2013). Discovering and supporting successful learning pathways of youth in and out of school: Accounting for the development of everyday expertise across settings. In B. Bevan et al. (Eds), LOST opportunities: Learning in out-of-school time (pp.119-140). Dordrecht, Netherlands: Springer.

Bills, D. B. (2003). Credentials, signals, and screens: Explaining the relationship between schooling and job assignment. Review of Educational Research, 73 (4), 441-449.

Boticki, I., Baksa, J., Seow, P., \& Looi, C. (forthcoming). Usage of a mobile social learning platform with virtual badges in a primary school. Computers \& Education.

Bowker, G. C., \& Star, S. L. (1999). Sorting things out: Classification and its consequences. Cambridge, MA: MIT Press.

Boyatzis, R. E. (1998). Transforming qualitative information: Thematic analysis and code development. Thousand Oaks, CA: Sage Publications, Inc.

Brown, J. S., Collins, A., \& Duguid, P. (1989). Situated Cognition and the Culture of Learning. Educational Researcher, 18 (1), 32-42.

Crowley, K., Barron, B. J., Knutson, K., \& Martin, C. (In press). Interest and the development of pathways to science. In Interest in mathematics and science learning and related activity, K. A. Renninger, M. Nieswandt, and S. Hidi (Eds.). Washington DC: AERA.

Davis, K. \& Fullerton, S. (forthcoming). Connected learning in and after school: Exploring technology's role in the diverse learning experiences of high school students. The Information Society.

Davis, K. \& Klein, E. (2015). Investigating high school students' perceptions of digital badges in afterschool learning. ACM Conference on Human Factors in Computing Systems (CHI'15). 
Denny, P. (2013). The effect of virtual achievements on student engagement. In Proceedings of the SIGCHI Conference on Human Factors in Computing Systems (pp. 763-772). New York, NY, USA: ACM.

Filsecker, M., \& Hickey, D. T. (2014). A multilevel analysis of the effects of external rewards on elementary students' motivation, engagement and learning in an educational game. Computers \& Education, 75 (1) 136-148.

Fullerton, S., Menking, A., Lee, C., \& Davis, K. (2014, April). Stakeholders' perceptions of the opportunities, challenges, and value of digital badges in education. Paper presented at the annual meeting of the American Educational Research Association, Philadelphia, PA.

Gibson, D., Ostashewski, N., Flintoff, K., Grant, S., \& Knight, E. (2013). Digital badges in education. Education and Information Technologies, 1-8.

Grant, S. (2014). What counts as learning: Open digital badges for new opportunities. The Digital Media and Learning Research Hub Report Series on Connected Learning.

Gutierrez, K.D., and Rogoff, B. (2003). Cultural ways of learning: Individual traits or repertoires of practice. Educational Research, 32, 19-25.

Halavais, A. M. C. (2012). A genealogy of badges. Information, Communication \& Society, 15(3), 354-373.

Hickey, D. T., \& McCaslin, M. (2001). Comparative and sociocultural analyses of context and motivation. In S. S. Volet \& S. Järvelä (Eds.), Motivation in learning contexts: Theoretical and methodological implications (pp. 33-56). Amsterdam: Pergamon/Elsevier.

Hohlfeld, T. N., Ritzhaupt, A. D., Barron, A. E., \& Kemker, K. (2008). Examining the digital divide in K-12 public schools: Four-year trends for supporting ICT literacy in Florida. Computers \& Education, 51 (4) 1648-1663.

Holland, D. C., Lachicotte, W., Skinner, D., \& Cain, C. (1998). Identity and agency in cultural worlds. Cambridge, Mass.: Harvard University Press.

Ito, M., Gutiérrez, K., Livingstone, S., Penuel, B., Rhodes, J., Salen, K., Schor, J., SeftonGreen, J., \& Watkins, S. C. (2013). Connected learning: an agenda for research and design. Digital Media and Learning Research Hub. Available at: http://dmlhub.net/sites/default/files/ConnectedLearning_report.pdf

Itow, R., \& Hickey, D. T. (2013, June 5). Design Principles for Assessing Learning with Digital Badges. RE-MEDIATING ASSESSMENT. Retrieved from 
http://remediatingassessment.blogspot.com/2013/05/design-principles-forassessing_30.html

Jenkins, H., Clinton, K., Purushotma, R., Robison, A.J., \& Weigel, M. (2009).

Confronting the challenges of participatory culture: Media education for the twenty-first century. Cambridge, MA: MIT Press.

Landis, J. R., \& Koch, G. G. (1977). The measurement of observer agreement for categorical data. Biometrics, 33(1), pp. 159-174.

Lave, J. (1988). Cognition in practice: Mind, mathematics, and culture in everyday life. Cambridge: Cambridge University Press.

Lave, J. \& Wenger, E. (1991). Situated learning: Legitimate peripheral participation. Cambridge [England]; New York: Cambridge University Press.

Maxwell, J. A. (2005). Qualitative research design: An interactive approach (2nd ed.). Thousand Oaks, CA: Sage Publications.

Miles, M. B., \& Huberman, A. M. (1994). Qualitative data analysis: An expanded sourcebook (2nd ed.). Thousand Oaks: Sage Publications.

Nasir, N.S., \& Cooks, J. (2009). Becoming a hurdler: How learning settings afford identities. Anthropology \& Education Quarterly, 40 (1), 41-61.

Nasir, N. S., \& Hand, V. (2008). From the court to the classroom: Opportunities for engagement, learning, and identity in basketball and classroom mathematics. Journal of the Learning Sciences, 17(2), 143-179.

Neuman, S. B., \& Celano, D. (2012). Giving our children a fighting chance: Poverty, literacy, and the development of information capital. New York: Teachers College Press.

Rehak, A., \& Hickey, D. T. (2013, May 20). Design Principles for Recognizing Learning. RE-MEDIATING ASSESSMENT. Retrieved from http://remediatingassessment.blogspot.com/2013/05/digital-badge-design-principlesfor.html

Restivo, M., \& van de Rijt, A. (2012). Experimental study of informal rewards in peer production. PLoS ONE, 7(3): e34358.

Riconscente, M.M., Kamarainen, A., \& Honey, M. (2013). STEM Badges: Current terrain and the road ahead. New York, NY: New York Hall of Science. Available at: http://badgesnysci.files.wordpress.com/2013/08/nsf_stembadges_final_report.pdf 
Rughinis, R. (2013). Talkative objects in need of interpretation. re-thinking digital badges in education. In CHI '13 Extended Abstracts on Human Factors in Computing Systems (pp. 2099-2108). New York, NY, USA: ACM. doi:10.1145/2468356.2468729

Schenke, K., Tran, C., \& Hickey, D. T. (2013, June 5). Design Principles for Motivating Learning with Digital Badges. RE-MEDIATING ASSESSMENT. Retrieved from http://remediatingassessment.blogspot.com/2013/06/design-principles-formotivating.html

Smagorinsky, P. (2008). The method section as conceptual epicenter in constructing social science research reports. Written Communication, 25(3), 389-411.

Star, S. L., \& Griesemer, J. R. (1989). Institutional ecology, 'translations' and boundary objects: Amateurs and professionals in Berkeley's Museum of Vertebrate Zoology, 1907-39. Social Studies of Science (Sage), 19(3), 387-420.

Vygotsky, L.S. (1978). Mind in society: The development of higher psychological processes. Cambridge, MA: Harvard University Press.

Wenger, E. (1998). Communities of practice: Learning, meaning, and identity. Cambridge, U.K: Cambridge University Press.

Zhong, Z. J. (2011). From access to usage: The divide of self-reported digital skills among adolescents. Computers \& Education, 56 (3) 736-746. 


\section{Appendix A. Coding Scheme}

\section{A. Personal awareness of badges}

\section{B. Badge opportunities}

B01. connect learning across contexts B02. provide visible, granular pathways, learning trajectories, micro-credentials

B03. supports assessment practices B04. public recognition beyond learning context

B05. actionable, use badges to unlock opportunities

B06. use badges to establish one's credibility, reputation, skills

B07. motivation: serves as a positive motivating force in learning

B08. empowerment, agency in hands of learner

B09. fairness, badges don't sort people like grades do

B10. supports social equity

B11. provides a permanent record of learning, accomplishments

B12. supports positive online presence

B13. "cool" factor of digital badges

B14. helps to show/display passion of students

B15. helps to show diversity of students, including their interests, accomplishments

\section{Badge challenges}

C01. privacy concerns; learner may not want connections to be made across contexts

C02. lack of granularity, everyone gets the same badge

C03. challenge of evaluating skills

C04. badges not externally, easily visible to others

C05. badges fail to unlock opportunities for learner

C06. challenge of establishing credibility, getting stakeholders to value badges C07, motivation: either fails to motivate or places undue emphasis on extrinsic rewards C08. top-down initiative, learner doesn't get a say in the design, awarding, use of badges

C09. unfair to use badges to sort people

C10. social equity, accessibility due to SES factors, worsening the digital divide

C11. ephemerality of digital artifacts, obsolescence

C12. ends vs. means, quantification of learning

C13. trivial badges, quantity vs. quality, issues of quality control

C14. technical challenges

C15. effort, work required, resources, time, money needed to implement, scale badges 
Table 1.

Frequency of opportunities discussed in relation to digital badges, by stakeholder.

\begin{tabular}{lllll}
\hline OPPORTUNITIES: $\mathbf{4 2 5}$ & $\mathbf{C P}^{\mathbf{2}}: \mathbf{7 1}$ & $\mathbf{T}^{\mathbf{2}} \mathbf{5 6}$ & $\mathbf{A N}^{\mathbf{2}}: \mathbf{1 7 5}$ & $\mathbf{S}^{\mathbf{2}} \mathbf{1 1 0}$ \\
\hline establish credibility: 125 & $20(28 \%)$ & $14(25 \%)$ & $52(30 \%)$ & $34(31 \%)$ \\
\hline actionability: 77 & $11(15 \%)$ & $4(7 \%)$ & $33(19 \%)$ & $24(22 \%)$ \\
\hline recognition: 70 & $14(20 \%)$ & $11(20 \%)$ & $19(11 \%)$ & $26(24 \%)$ \\
\hline visible, granular pathways: 42 & $8(11 \%)$ & $2(4 \%)$ & $28(16 \%)$ & $4(4 \%)$ \\
\hline motivation: 31 & $5(7 \%)$ & $12(21 \%)$ & $4(2 \%)$ & $10(9 \%)$ \\
\hline empowerment: 26 & $3(4 \%)$ & $6(11 \%)$ & $13(7 \%)$ & $4(4 \%)$ \\
\hline connect learning: 19 & $2(3 \%)$ & $1(2 \%)$ & $14(8 \%)$ & $2(2 \%)$ \\
\hline equity: 9 & $1(1 \%)$ & 0 & $7(4 \%)$ & 0 \\
\hline
\end{tabular}

${ }^{1}$ Because only the top opportunities are reported, the total opportunities add up to more than the individual opportunities in each column.

${ }^{2}$ CP: community partner; T: teacher of record; AN: Afterschool Network staff; S: student

Note: Shaded cells represent the top three most frequently cited opportunities, with the darkest shade representing the most frequently cited opportunity. 
Table 2.

Frequency of challenges discussed in relation to digital badges, by stakeholder.

\begin{tabular}{lllll}
\hline CHALLENGES: 352 & $\mathbf{C P}^{\mathbf{2}}: \mathbf{4 7}$ & $\mathbf{T}^{\mathbf{2}} \mathbf{2 8}$ & $\mathbf{A N}^{\mathbf{2}}: \mathbf{1 6 4}$ & $\mathbf{S}^{\mathbf{2}} \mathbf{1 0 6}$ \\
\hline establish credibility: 110 & $19(40 \%)$ & $10(36 \%)$ & $35(21 \%)$ & $43(41 \%)$ \\
\hline effort, work, resources: 46 & $1(2 \%)$ & 0 & $44(27 \%)$ & 0 \\
\hline badges not externally visible: 38 & $5(11 \%)$ & $12(43 \%)$ & $2(1 \%)$ & $17(16 \%)$ \\
\hline trivial badges: 27 & 0 & 0 & $14(9 \%)$ & $9(8 \%)$ \\
\hline technical challenges: 24 & $3(6 \%)$ & 0 & $19(12 \%)$ & $2(2 \%)$ \\
\hline motivation: 18 & $8(17 \%)$ & 0 & $4(2 \%)$ & $6(6 \%)$ \\
\hline lack of granularity: 18 & $2(4 \%)$ & $1(4 \%)$ & $8(5 \%)$ & $7(7 \%)$ \\
\hline social equity: 15 & $1(2 \%)$ & 0 & $14(9 \%)$ & 0 \\
\hline top-down: 14 & $3(6 \%)$ & 0 & $9(5 \%)$ & $2(2 \%)$ \\
\hline does NOT unlock opportunities: 11 & $1(2 \%)$ & 0 & $7(4 \%)$ & $3(3 \%)$ \\
\hline privacy: 10 & 0 & 0 & 0 & $10(9 \%)$ \\
\hline ends vs. means: 9 & $3(6 \%)$ & 0 & $5(3 \%)$ & $1(1 \%)$ \\
\hline
\end{tabular}

${ }^{1}$ Because only the top challenges are reported, the total challenges add up to more than the individual challenges in each column.

${ }^{2} \mathrm{CP}$ : community partner; T: teacher of record; AN: Afterschool Network staff; S: student Note: Shaded cells represent the top three most frequently cited challenges, with the darkest shade representing the most frequently cited challenge. 
Digital Badges in Afterschool Learning

\section{Acknowledgements}

The authors wish to thank the Bill and Melinda Gates Foundation for funding this research. 